\title{
THE MANAGEMENT OF INEBRIATES.
}

\author{
BY JOSEPH S. BOLTON, M.D., G.M., M.R.G.S.
}

No census of the number of inebriates in this country has ever been taken, but there can be no doubt that they total many thousands. The majority of them are under no proper care or subject to any rational management. They are just allowed to roam unrestricted, distressing their friends, squandering their money, and breaking up their homes.

Dr. Branthwaite* tells us that inebriety is frequently a form of insanity, and he therefore naturally asks for better legal control. Indeed, for a large class of inebriates he would apparently regard incarceration for life as the only proper course to pursue. But his paper refers rather to the mentally defective class of inebriate. According to reliable returns, something like 70 per cent. of the inebriates in our State reformatories belong to the feeble-minded class. ${ }^{\dagger}$

Dr. Mary Gordon, $\ddagger$ holding the same view, would apparently be hopeful for the result of a long term of detention-three years or longer, as the case might require. Such advice as this is enough to damp the ardour of the most earnest reformer as he contemplates the vast army of inebriates. But in spite of this pessimistic view, out of the darkness there comes a ray of light, for before bringing her paper to a close she makes the following statement : "One of the most remarkable features of the disease

* British Journal of Inebriety, January, 1908.

+ See "Report of and Minutes of Evidence taken before the Departmental Committee appointed to inquire into the Operations of the Law relating to Inebriates, and to their Detention in Reformatories and Retreats"; "The Report of the Royal Commission on the Poor Laws and the Relief of Distress"; and "Report of the Royal Commission on the Care and Control of the Feeble-minded."

$\ddagger$ British Journal of Inebriety, January, 1907. 


\section{The British Journal of Inebriety}

is the way in which it will occasionally yield to unexpected, and, one would have thought, inadequate means." Indeed, she goes still further when she says: "We know that a large proportion of alcoholic cases can be improved or practically cured." Now, with this sentence $I$ so heartily agree that $I$ must be excused for repeating it. I would make it the text of this article: " $A$ large proportion of alcoholic cases can be improved or practically cured." The reformer may take heart again. He has but to investigate the methods by which these cases are being cured and to proceed on those lines. But when we come to examine the methods we are perplexed at their number and diversity. Dr. Gordon details a few of them: "Some men and women make a plucky resistance, and cure themselves; some are cured if the exciting cause is removed, some by terrorizing, some by prayer-meetings, some by tribulation, some by happiness, some by an altered point of view, some by food, or drugs, or improved general health."

In looking through this list one naturally asks : "Is there any underlying principle which is common to them all ?" The answer comes: "A profound impression was produced upon the patient -so powerful that it was able to inhibit the craving for alcohol." The question of cure in any particular case depends upon whether we can provide the "stronger than he." A something more powerful than the power in possession. As aptly expressed by Dr. Chalmers: "The expulsive power of a new affection." This, then, is the problem, and it should be taken up in earnest by every family doctor, and not be left to be exploited by the quack. The remedy may be mental, moral, or physical, or may combine all three. We of the medical profession are accustomed to treat the mind through the body, and that not by any rule of thumb; we treat each case on its merits. Let us apply the same commonsense methods to the treatment of the inebriate, and we shall in a good proportion of cases succeed.

The question must be faced: "Why did the patient fall a victim to this disease of inebriety? Was it some inherent weakness in the character, or was it the result of his surroundings?" Unless the defect can be permanently remedied the morbid state will occur again.

We are met at the outset with a difficulty which does not usually occur in treating other diseases. Oftentimes the patient does not wish to be cured. If this difficulty cannot be overcome the case is very hopeless. It is impossible to cure a patient of inebriety 


\section{The British Journal of Inebriety}

against his will. The desire to be restored is not, however, essential as a preliminary to treatment. Many inebriates are so besotted that they cannot entertain a fixed desire. They have to be sobered down first and made able to take a reasonable view of their condition.

The next important indication is to inspire hope. Many a patient has become so accustomed to fall before his enemy that he has given up the fight. Hence the importance of convincing him and his friends that success is certain if they will only follow the directions given. The cock-suredness of the quack is apt to be lacking in the qualified doctor. It often makes all the difference between success and failure. Let the patient feel that the doctor is interested in his condition, and has the evident intention of curing him. The symptoms must then be treated as they arise. A few days in bed under a reliable nurse is sometimes necessary. If the patient is suffering from mental excitement which makes him a danger to himself and a terror to his friends, a hypodermic of apomorphine will often immediately restore calm and sleep. The rapid relief wrought by this drug will not only relieve present distress but will so impress the patient with the power the doctor has over his disease that it will go far to reinforce the profound impression which is necessary for a cure. Other hypnotics in large doses are sometimes useful, as are also calomel and carminatives. But the pièce de résistance is atropine. This drug is the nearest approach to a specific for inebriety that we possess. To obtain immediate and certain benefit it must be administered hypodermically. The stomach of a drunkard is not usually in a condition to receive and absorb either drugs or food. Then, again, the hypodermic method keeps up the wholesome impression already produced upon the patient's mind. But is the drug of any real value, or would the injection of water answer the same purpose? To this question I can give an emphatic answer. After long trial of the use of atropine in large and small doses, I can say without fear of contradiction, "It will remove the craving for alcohol from every person who wishes to have it removed." Living witnesses to the truth of this opinion can be produced, and would, I think, satisfy the most sceptical.

It is usual to combine strychnine with the atropine injected. Experienced physicians agree that it is a powerful tonic, and well calculated to aid in the restoration of the system disorganized by alcohol. 
Much has been written about the danger of the patient learning to use the hypodermic syringe, and so forming a habit worse than the alcoholic one. This danger, in my opinion and experience, does not exist. I have yet to find the doctor who would leave a patient in agony rather than administer a hypodermic of morphine. Yet there is grave risk of a patient learning the morphia habit. But I have never seen or heard of a patient who contracted a habit of using atropine or strychnine.

By the use of these drugs we are able to remove the craving for alcohol, and restore the patient to health and vigour. Being now in his right senses, with a healthy appetite and ability to work and face the world, he is able to take a rational and serious view of life, and plan out for himself a path of safety for the future.

There are thousands of inebriates in this country who just need this start. Relapses may occur, but they can often be forestalled and frequently prevented. If there is a tendency to recurrence every month, or every three months, there will usually be some aura or premonitory symptom of restlessness or change of disposition which will warn the patient and his friends of the coming danger. A timely visit to the family doctor, a few injections, and all will be well again. Every month which passes in safety will make the future outlook more certain. The powers of self-control, once lost, are not easily regained. It is a matter requiring years rather than months. This power cannot well be developed in an institution ; long periods of detention unfit the patient for the battle of life. A Royal Commission has sat and heard evidence and given advice, but I fear not one patient is a whit the better for all the time and money spent. They refused to receive evidence from those who were actually curing the inebriate. Their advice appears to me to amount to this: "Do nothing till the inebriate has become very bad, too bad to be kept at home; then send him to an institution for a long period, and after he comes out place him under an after-care association." Surely it would be more reasonable to try to stop an inebriate before he or she has fallen so low-to check the disease in its initial stages. 